\title{
Effect of connection procedures on the behaviour of RC columns strengthened with RC layers and jackets
}

\author{
A. P. Lampropoulos, O. T. Tsioulou \& S. E. Dritsos \\ Department of Civil Engineering, University of Patras, Greece
}

\begin{abstract}
This study examines the behaviour of reinforced concrete (RC) columns strengthened with either a RC jacket or an additional RC layer.

The main object of this work was to evaluate the behaviour of the strengthened specimens for different connection procedures used to bond the old and new concrete. For the column strengthened with a concrete jacket, the effect of the roughness of the interface on the behaviour of the strengthened specimen was examined. For the column strengthened using an additional RC layer, the presence of shear connectors between the old and new reinforcement was also examined to provide adequate connection between the two concrete members. The strength degradation of the interface because of the cyclic loading was taken into account. Using the results of the analyses, monolithic coefficients (these are special coefficients that correlate the behaviour of the strengthened specimens to the respective monolithic) were calculated for the different connection procedures examined.
\end{abstract}

Keywords: concrete, column, strengthening, jacket, finite element, interface, friction, cohesion, shear connectors.

\section{Introduction}

Strengthening of RC columns using additional concrete layers and jackets perimetric to the initial element is a quite common technique used for the strengthening of RC members. However, there are many uncertainties about the behaviour of the strengthened elements. The finite element method was used to examine the behaviour of columns strengthened with $\mathrm{RC}$ jacket or additional RC 
layers. The ATENA software was used in this study, as it was previously found to be appropriate for the accurate prediction of the behaviour of RC elements, even in the post peak region of the load deflection curve (Lampropoulos and Dritsos [6]).

A major issue in modeling composite elements, such as the above columns, is the simulation of the interface between the old and new concrete. Thus, appropriate contact elements have been used in this study to simulate the interface. The effect of cyclic loading on the behaviour of the interface is also important and, thus, a methodology, proposed by Lampropoulos and Dritsos [5], for the strength degradation of the interface using the finite element method was used to accurately predict the behaviour of the strengthened specimens under earthquake loading.

Using the results obtained from the analyses of the strengthened specimens, monolithic factors have been calculated. Monolithic factors are special correction factors that can be used to define the behaviour of the strengthened element by comparing it with the behaviour of the respective monolithic element. Monolithic factors for the stiffness, resistance, deformation and ductility, are defined as the ratio of the stiffness, strength, deformation and ductility of the strengthened element over the stiffness, strength, deformation and ductility of the respective monolithic element. These factors can be calculated at the characteristic points of the load-deflection curve (i.e. yield, maximum load capacity, failure).

\section{Geometry and material properties}

In this study, a RC column strengthened with $\mathrm{RC}$ jacket and another one strengthened with additional RC layer were examined. In addition, different interface conditions were examined.

The cross sectional dimensions of the original column were 250 by $250 \mathrm{~mm}$ and its height was $1800 \mathrm{~mm}$. The thickness of the jacket was $75 \mathrm{~mm}$ and its height was $1300 \mathrm{~mm}$. The concrete strength of the initial column was $27 \mathrm{MPa}$ and for the jacket was $55.8 \mathrm{MPa}$. The longitudinal reinforcement of the initial column was 4 bars of $14 \mathrm{~mm}$ diameter (steel grade S220), and stirrups $8 \mathrm{~mm}$ diameter steel (grade S220) with a spacing of $200 \mathrm{~mm}$. In the jacket, the longitudinal reinforcement was 4 bars of $20 \mathrm{~mm}$ diameter (steel grade S500), and the stirrups were $10 \mathrm{~mm}$ diameter (steel grade S500) with a spacing of $100 \mathrm{~mm}$. The reflected value for the axial load in the original column was 0.4 and a horizontal displacement was applied at the top of the column. The column was fixed to a strong footing (fig. 1).

The strengthened column with the additional layer had exactly the same geometry and the same material properties with the one with the concrete jacket. The reinforcement of the additional layer was 2 longitudinal bars of $20 \mathrm{~mm}$ diameter and steel grade S500. The loading conditions were the same to the strengthened specimen with the concrete jacket, described above. Figure 1 presents the finite element models used for the analyses. 

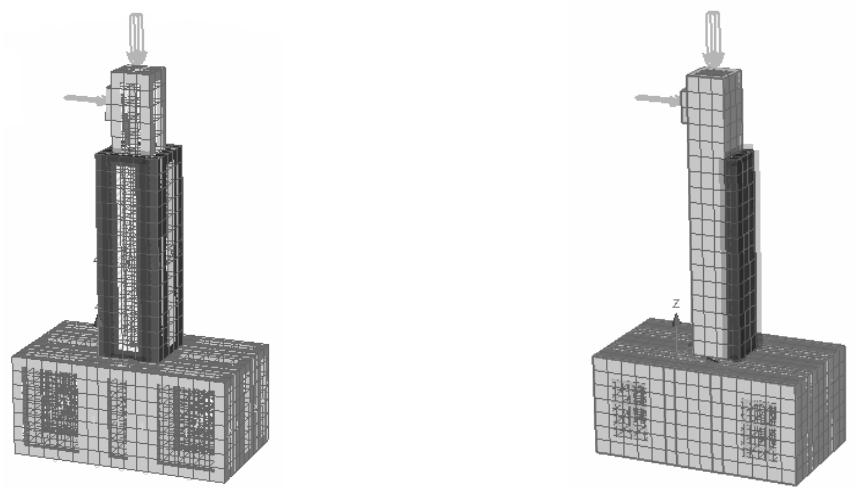

Figure 1: $\quad$ Finite element models for the column strengthened with jacket and with additional layer.

\section{Analytical work}

As mentioned above, the ATENA finite element software was used to perform the analyses. The stress-strain curve proposed by CEB-FIP Model Code 1990, CEB-fib [2], was used to simulate the behaviour of concrete in compression, (fig. 2).

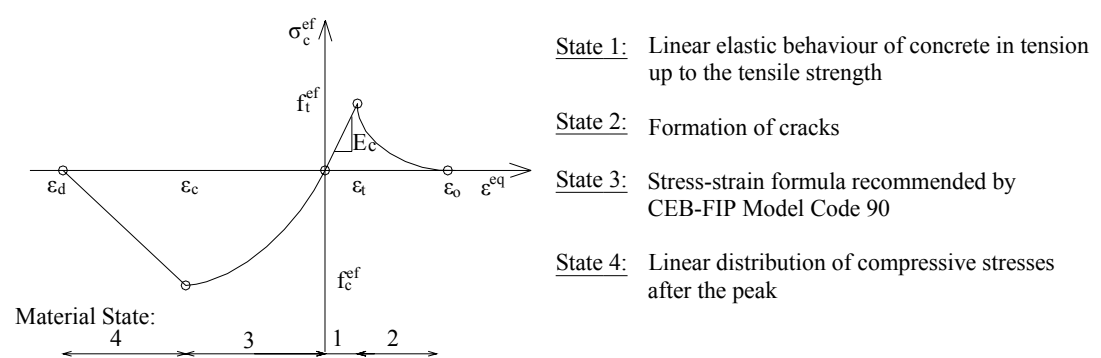

Figure 2: $\quad$ The stress-strain behaviour of concrete.

The element, used to simulate the bar reinforcement, was a link element with bilinear stress-strain behaviour with strain-hardening. This element is capable of including relative slip with the concrete element using three different reinforcement bond models (Cervenka et al [3]). For the analyses carried out, the model proposed by the CEB-FIP Model Code 1990 was used.

The interface between the old and new concrete was simulated using special contact elements. These elements were considered to be fixed at the footing and free at the top. A contact pair, consisting of two special contact elements was used to simulate the behaviour of the interface. The first contact element was a 
target surface that modelled the surface of the new concrete, while the second was a contact surface that modelled the surface of old concrete. The model, used to define the behaviour of the contact elements, is presented in figure 3 .

The behaviour at the interface can be simulated using the contact elements and appropriate values for the coefficients of friction $(\mu)$ and cohesion (c). However, the behaviour of the interface is affected by the cyclic loading. To include the effect of the cyclic loading on the strength degradation of the interface, the procedure proposed in a study by Lampropoulos and Dritsos [5] was used for the cyclic loading presented in figure 4a. According to this procedure, the ratio of the reduced coefficient of friction to the initial coefficient of friction (in the first loading cycle) was calculated for each load cycle (fig. 4b). The lower value for the coefficient of friction is considered to be 0.4. After this value, it is considered to remain constant.

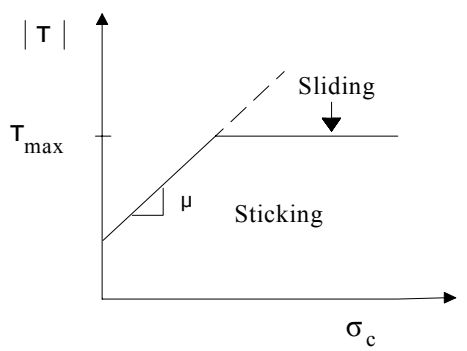

$$
\begin{aligned}
& \tau_{\max }=\mu \sigma_{\mathbf{c}}+\mathbf{c} \\
& \left|\tau_{\text {shear }}\right| \leq \boldsymbol{\tau}_{\max } \\
& \text { where: } \\
& \tau_{\text {max }}=\text { maximum friction stress, } \\
& \left|\boldsymbol{\tau}_{\text {shear }}\right|=\text { shear stress, } \\
& \boldsymbol{\mu}=\text { coefficient of friction, } \\
& \mathbf{c}=\text { coefficient of cohesion and } \\
& \boldsymbol{\sigma}_{\mathbf{c}}=\text { normal stress in the interface. }
\end{aligned}
$$

Figure 3: $\quad$ Shear stress against normal stress distribution at the interface.

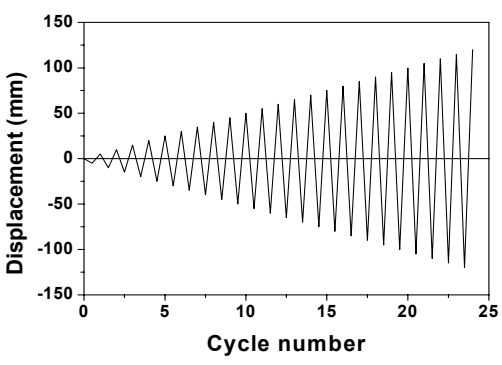

(a)

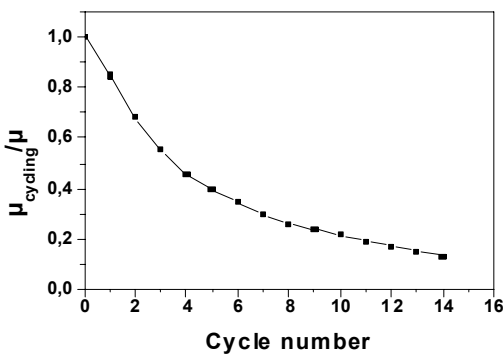

(b)

Figure 4: (a) Cyclic loading, (b) reduction ratio for the coefficient of friction.

For the column strengthened with the perimetric RC jacket, three different analyses were performed. The following values were used for the coefficients of friction and cohesion: a) $\mu=0.4-\mathrm{c}=1 \mathrm{MPa}$ [Specimen $\left.\mathrm{RMJ}_{1}\right]$, b) $\mu=1-\mathrm{c}=1 \mathrm{MPa}$ [Specimen $\mathrm{RMJ}_{2}$ ] and c) $\mu=1.55-\mathrm{c}=1 \mathrm{MPa}$ [Specimen $\left.\mathrm{RMJ}_{3}\right]$. The values for the coefficient of friction - for the specimens $\mathrm{RMJ}_{2}$ and $\mathrm{RMJ}_{3}$ - were reduced during the analysis by using the ratio shown in figures $4 \mathrm{~b}$ (fig. 5). The cohesion was considered to be equal to $0.5 \mathrm{MPa}$ after the first loading cycle and equal to zero 
after the second loading cycle. A monolithic specimen with the same geometry to the strengthened was also examined [Specimen $\mathrm{RMJ}_{\text {monolithic }}$.

For the strengthened model with the additional layer in the compressive side of the original column, three analyses with the following coefficients of friction and cohesion were carried out: a) $\mu=0.4-\mathrm{c}=1 \mathrm{MPa}$ [Specimen $\mathrm{RML}_{1}$ ], b) $\mu=1-\mathrm{c}$ $=1 \mathrm{MPa}$ [Specimen $\mathrm{RML}_{2}$ ] and c) $\mu=1.55-\mathrm{c}=1 \mathrm{MPa}$ [Specimen $\mathrm{RML}_{3}$ ]. It was assumed that the model for the reduction of the coefficient of friction (presented in figure 4b) can also be applied for the case of RC elements strengthened with an additional layer. The coefficient of friction was reduced using the ratio shown in figure $4 b$; the values used during the analysis are depicted in figure 5 . The cohesion was considered to be equal to $0.5 \mathrm{MPa}$, after the first loading cycle, and equal to zero, after the second loading cycle.

Two additional analyses were performed, one with the original column [Specimen RM] and another one with a monolithic column that had the same geometry as the strengthened specimen [Specimen $\mathrm{RML}_{\text {monolithic]. According to }}$ the response of the strengthened column, it was evaluated that the strength of the composite specimens was much lower than the one of the respective monolithic specimen. To increase the strength of the composite specimens, special shear connectors were used between the old and new reinforcement [Specimen $\mathrm{RML}_{\mathrm{SC}}$ ], (fig. 6). Four connectors, $10 \mathrm{~mm}$ in diameter and steel grade S220, were placed along the height of the column to connect the old with the new reinforcement. The values for the coefficients of friction and cohesion were the same as the values used for specimen $\mathrm{RML}_{2}$. Figure 6 shows a view of the shear connector between the old and new reinforcement.

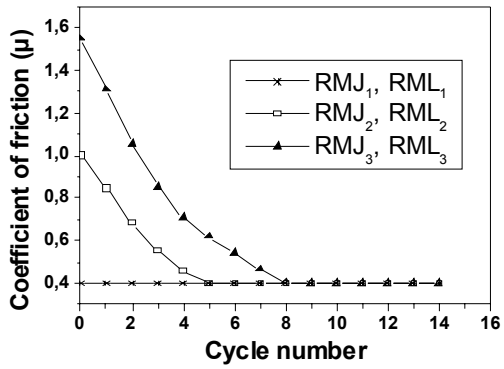

Figure 5: Values for the coefficient of friction in each loading cycle for the models examined.

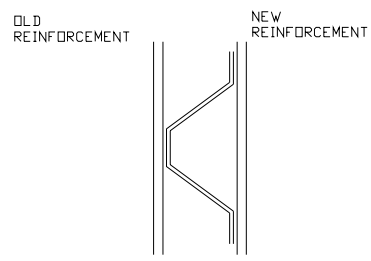

Figure 6: Shear connectors between the old and new reinforcement. 


\section{Results}

The load-deflection results of the analyses are presented in this section. The load-deflection curves were converted to idealized two-linear curves. In order to establish a bilinear idealization, the rule of equal energy under the capacity curve has been adopted in a similar way to that described in ATC 40 [1] and GRECO [4], so that the total energy up to the maximum force is the same for both the load-deflection curve and the bilinear idealization. The failure load, $\mathrm{P}_{\mathrm{u}}$, is defined as the lateral load that is $20 \%$ less than $\mathrm{P}_{\max }$ and the failure displacement, $\delta_{\mathrm{u}}$, corresponds to this failure load.

According to the idealized curves, the characteristic points for the yield, maximum load capacity and failure of the specimen were defined. The ductility (displacement at failure / displacement at yield) was also calculated. The results for the strengthened column with the perimetric jacket are shown in figure 7 .

Using the results presented in figure 7, monolithic factors for the displacement and strength at yielding $\left(\mathrm{k}_{\delta \mathrm{y}}, \mathrm{k}_{\mathrm{Fy}}\right)$, maximum load $\left(\mathrm{k}_{\delta \max }, \mathrm{k}_{\mathrm{Fmax}}\right)$ and failure $\left(\mathrm{k}_{\delta \mathrm{u}}, \mathrm{k}_{\mathrm{Fu}}\right)$ were calculated. Monolithic factors for the stiffness at yielding $\left(\mathrm{k}_{\mathrm{ky}}\right)$ and failure $\left(\mathrm{k}_{\mathrm{ku}}\right)$ and for ductility $\mathrm{k}_{\text {duct. }}$ were also calculated. These values are presented in table 1 .

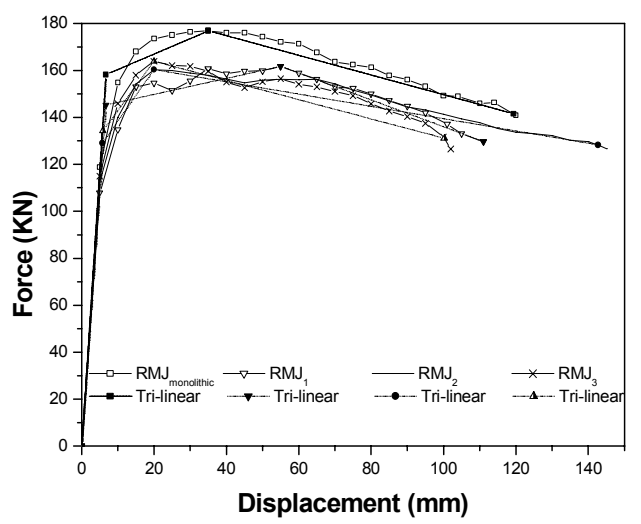

Figure 7: Load-deflection curves for the specimens $R M J_{\text {monolithic }} R M_{1^{-}}$ $\mathrm{RMJ}_{2}-\mathrm{RMJ}_{3}$.

Table 1: $\quad$ Values for the monolithic factors.

\begin{tabular}{l|ll|lll|lll}
\hline Specimen & $\mathrm{k}_{\delta \mathrm{y}}$ & $\mathrm{k}_{\mathrm{Fy}}$ & $\mathrm{k}_{\delta \max }$ & $\mathrm{k}_{\delta \mathrm{u}}$ & $\mathrm{k}_{\text {Fmax/u }}$ & $\mathrm{k}_{\mathrm{ky}}$ & $\mathrm{k}_{\mathrm{ku}}$ & $\mathrm{k}_{\text {duct. }}$ \\
\hline $\mathrm{RMJ}_{1}$ & 1.01 & 0.92 & 1.57 & 0.93 & 0.91 & 0.91 & 0.98 & 0.92 \\
$\mathrm{RMJ}_{2}$ & 0.86 & 0.81 & 0.57 & 1.20 & 0.91 & 0.95 & 0.76 & 1.39 \\
$\mathrm{RMJ}_{3}$ & 0.88 & 0.85 & 0.57 & 0.84 & 0.93 & 0.97 & 1.11 & 0.96 \\
\hline
\end{tabular}

According to the results of the strengthened specimens, presented in table 1, it can be seen that there was a slight increase of the maximum load and the load at failure in specimen $\mathrm{RMJ}_{3}$ in relation to the other two strengthened models 
$\mathrm{RMJ}_{1}, \mathrm{RMJ}_{2}$. The load at yielding obtained for specimen $\mathrm{RMJ} \mathrm{J}_{1}$ was larger than that evaluated for the other two strengthened specimens. Furthermore, the displacement at failure and as a result the ductility of the specimen $\mathrm{RMJ}_{2}$ were found to be the largest values calculated for the strengthened specimens. According to the load-deflection curve and up to a deflection equal to $30 \mathrm{~mm}$, it is obvious that there was an increment in the load capacity for the strengthened specimen when larger values for the coefficient of friction were used. The results using the characteristic points at yield, at maximum load and at failure seem to be more complicated because the load-deflection curve was converted to idealized tri-linear and because of the fact that the coefficient of friction was reduced during the analyses of the specimens $R M J_{2}$ and $R M J_{3}$. However, it is obvious that there were not significant differences between the results obtained for the different values of the coefficient of friction. This is because the effect of cyclic loading on the strength of the interface was taken into account. As a result, the values for the coefficient of friction, for the different models examined, became very similar and exactly the same after the first loading cycles (fig. 5). The results obtained for the strengthened specimens with the additional layer in the compressive side are presented in figure 8.

It is obvious from figure 8 that when an additional layer is used to strengthen the original column, roughening the interface between the old and new concrete cannot provide adequate connection and, hence, the use of shear connectors is vital. From the same results plotted in figure 8, the values for the load and deflection at the characteristic points of yielding, maximum load and failure were calculated. These values were then used to calculate the monolithic coefficients (Table 2).

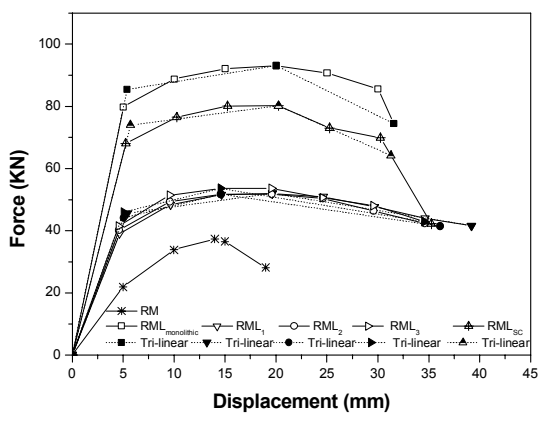

Figure 8: Load-deflection curves for the column strengthened with additional layer.

As in the case of the original column strengthened with an $\mathrm{RC}$ jacket, there were not significant differences in the results obtained for the different values of the coefficient of friction and cohesion. However, by using shear connectors in the interface between the old and new concrete, the strength of the specimen was increased significantly. To justify this behaviour, the sliding in the interface was examined. Two analyses, with and without shear connectors (Specimens 
RMLCFC $_{\mathrm{SC}}$ and RMLCFC respectively) were performed. The coefficient of friction was considered to be equal to 1 and cohesion equal to $1 \mathrm{MPa}$; these values were kept constant during the analysis. The effect of cyclic loading on the strength degradation of the interface was omitted to simplify the investigation. The load-deflection curves and the sliding at a point on the compressive side of the interface - along the height of the column - are shown in figure 9 .

Table 2: $\quad$ Monolithic factors calculated for specimens strengthened with an additional layer.

\begin{tabular}{l|ll|lll|lll}
\hline Specimen & $\mathrm{k}_{\delta \mathrm{y}}$ & $\mathrm{k}_{\mathrm{Fy}}$ & $\mathrm{k}_{\delta \max }$ & $\mathrm{k}_{\delta \mathrm{u}}$ & $\mathrm{k}_{\mathrm{Fmax} / \mathrm{u}}$ & $\mathrm{k}_{\mathrm{ky}}$ & $\mathrm{k}_{\mathrm{ku}}$ & $\mathrm{k}_{\text {duct. }}$ \\
\hline $\mathrm{RML}_{1}$ & 1.01 & 0.53 & 0.98 & 1.24 & 0.56 & 0.53 & 0.45 & 1.23 \\
$\mathrm{RML}_{2}$ & 0.94 & 0.52 & 0.73 & 1.14 & 0.56 & 0.55 & 0.49 & 1.22 \\
$\mathrm{RML}_{3}$ & 0.94 & 0.54 & 0.73 & 1.09 & 0.57 & 0.57 & 0.52 & 1.16 \\
$\mathrm{RML}_{\mathrm{SC}}$ & 1.05 & 0.86 & 1.01 & 0.99 & 0.86 & 0.81 & 0.87 & 0.94 \\
\hline
\end{tabular}
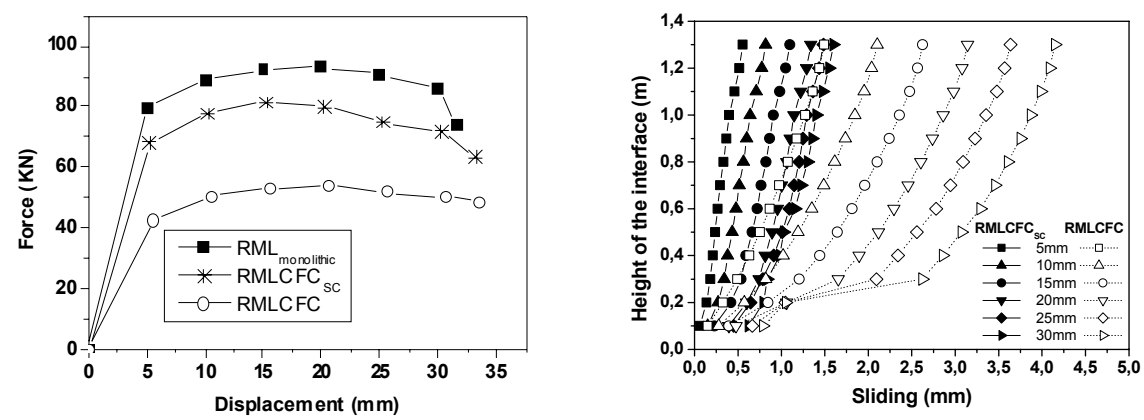

Figure 9: Load-deflection curves and sliding at the interface for the specimens $\mathrm{RMLCFC}_{\mathrm{SC}}$ and RMLCFC.

According to figure 9, it is obvious that the values for the sliding in the interface for the specimen RMLCFC are much larger than the respective values for the specimen RMLCFC $\mathrm{SC}_{\mathrm{SC}}$.

Figure 10, compares the monolithic factors calculated for the strength and stiffness at yielding and failure, for specimens strengthened using an additional RC layer and jacket. The strength and stiffness' monolithic factors (at yielding and failure), calculated for the columns strengthened with a perimetric jacket, are larger than the values determined for the columns strengthened in their compressive side with an additional concrete layer.

\section{Conclusions}

According to the results presented in this work, the following conclusions can be drawn. 


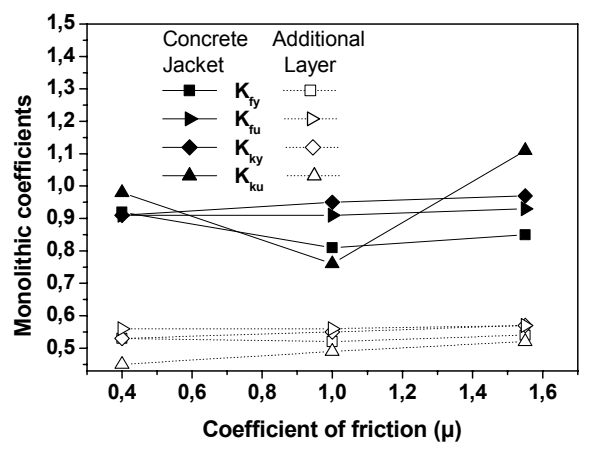

Figure 10: Monolithic factors using concrete jacket and additional layer.

(a) When the effect of the cyclic loading on the strength degradation of the interface is taken into account, the increase of the coefficient of friction, which simulates the strengthening of the interface, does not have a serious influence on the behaviour of the strengthened specimens.

(b) When $\mathrm{RC}$ jacket is constructed perimetric to the original column, the roughening of the interface between old and new concrete can ensure a quite adequate connection between the two members.

(c) Strengthening with additional RC layer requires shear connectors at the interface. If there are not shear connectors, then the strength of the composite specimen is much lower than that of the respective monolithic specimen, even for a well roughened interface.

(d) It was found that when an RC column is strengthened with an RC layer and there no shear connectors between the old and new reinforcement, there are large values for the sliding in the interface between the layer and the original column. The use of shear connectors, results in the significant reduction of the values of the sliding.

(e) According to the strength and stiffness' monolithic factors calculated for specimens strengthened with an additional RC layer and jacket, it was determined that the higher values were obtained when a perimetric jacket was used.

\section{Acknowledgement}

The contribution of Dr. Kyriacos Neocleous to the preparation of this manuscript is greatly acknowledged.

\section{References}

[1] ATC-40, Seismic evaluation and retrofit of concrete buildings, Applied Technology Council, Vol 1, California, USA, 1996. 
[2] CEB-fib, CEB-fib Model Code 1990, Comite Eurointernational du Beton, Thomas Telford, London, 1993.

[3] Cervenka, V. Jendele, L. \& Cervenka, J., ATENA Program Documentation Part 1 Theory, Prague, 2005.

[4] GRECO, Draft Version "Greek Retrofitting Code" by the Greek Organization for Seismic Planning and Protection, Greek Ministry for Environmental Planning and Public Works, Athens, 2005 (In Greek).

[5] Lampropoulos, A. \& Dritsos, S., Numerical Prediction of Behaviour of Strengthened R.C. Columns under Cyclic Loading, Proc of 11th International Conference on Structural Faults and Repair, Edinburgh, UK, 2006.

[6] Lampropoulos, A. \& Dritsos, S., Prediction of the Behaviour of Strengthened R.C. Columns using Finite Elements, 15th Concrete Conference TEE, Alexandroupoli, Greece, 2006 (In Greek). 